DOI: $10.14451 / 2.124 .89$

\title{
ПЕРСПЕКТИВЫ ПЛАНИРОВАНИЯ ЧЕЛОВЕЧЕСКИХ РЕСУРСОВ В ПРОЦЕССЕ СТРАТЕГИЧЕСКОГО УПРАВЛЕНИЯ АКТИВАМИ ВЫСШЕГО УЧЕБНОГО ЗАВЕДЕНИЯ
}

\author{
(c) 2018 Николаева Елена Анатольевна \\ кандидат социологических наук, доцент, кафедра иностранных языков № 3 \\ Российский экономический университет им. Г.В. Плеханова» \\ 115093, г. Москва, Стремянный пер., 36 \\ E-mail: yoltash82@mail.ru \\ (c) 2018 Кузнецова Юлия Андреевна \\ кандидат экономических наук, доцент, кафедра иностранных языков № 3 \\ Российский экономический университет им. Г.В. Плеханова \\ 115093, г. Москва, Стремянный пер., 36 \\ E-mail:yulia_success@mail.ru \\ (c) 2018 Панченко Екатерина Юрьевна \\ старший преподаватель, кафедра иностранных языков № 3 \\ Российский экономический университет им. Г.В. Плеханова \\ 115093, г. Москва, Стремянный пер., 36 \\ E-mail:katya368@yandex.ru \\ (c) 2018 Пронина Ирина Валерьевна \\ старший преподаватель, кафедра иностранных языков № 3 \\ Российский экономический университет им. Г.В. Плеханова \\ 115093, г. Москва, Стремянный пер., 36 \\ E-mail: irina.pronina@gmail.com
}

Актуальность вопроса стратегического управления активами в аспекте планирования человеческих ресурсов высшего учебного заведения на фоне комплексной и многоаспектной модернизации системы профессионального образования не вызывает сомнения. Объектом исследования выступил процесс стратегического планирования активами высшего учебного заведения, а предметом - перспективы планирования в нем человеческих ресурсов. Теоретическое и методологическое значение статьи заключается в развитии функциональной нагрузки перспектив планирования человеческих ресурсов при стратегическом управлении активами высшего учебного заведения, а практическое - в обозначении значимых перспектив в выбранном направлении.

Ключевые слова: высшее учебное заведение, процесс, перспективы, планирование, человеческие ресурсы, стратегическое планирование, стратегическое управление активами.

На современном этапе развития экономической системы Российской Федерации в условиях динамично меняющегося воздействия внешней среды на экономические субъекты сферы образования лидирующую позицию в процессе стратегического планирования их деятельности [3, с.89] приобретает управление активами, которые представлены материальными (движимое и недвижимое имущество, запасы и прочие материальные ценности) и нематериальными (деловая репутация; произведения науки; изобретения и программы для электронных вычислительных машин; полезные модели; селекционные дости- жения; ноу-хау; товарные знаки и знаки обслуживания) компонентами [1].

Согласно данным авторитетных исследователей Делойт Туш Томацу Лимитед в области стратегического управления активами [4] структура последних в высших учебных заведениях за последние пятнадцать лет во всем мире претерпела значительные изменения [5].

Динамика соотношения материальных и нематериальных активов в высших учебных заведениях различных стран по состоянию на начало 2013 и 2018 годов приведена на рисунке 1.

Из рисунка 1 можно увидеть, что с 2003 по 


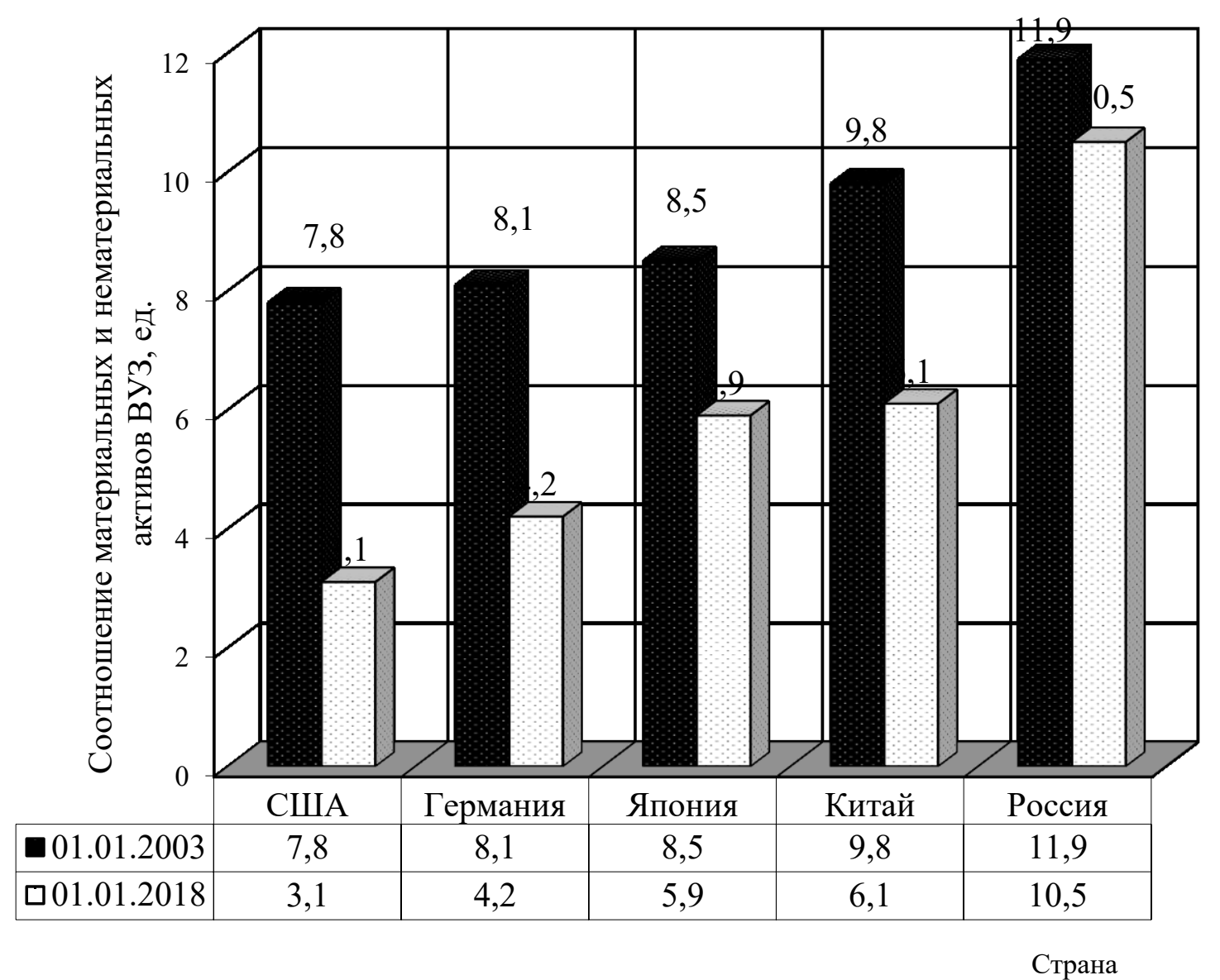

Puc. 1. Динамика соотношения материальных и нематериальных активов в высших учебных заведениях различных стран по состоянию на начало 2013 и 2018 годов [4]

2018 годы во всех без исключения анализируемых странах возросла доля нематериальных активов, однако сама динамика роста была различной. Так, например, для США соотношение материальных и нематериальных активов изменилось с 7,8 до 3,1 единиц (доля нематериальных активов здесь возросла в 2,52 раза).

Аналогичная по темпу роста ситуация имела место для высших учебных заведений Германии, доля нематериальных активов которых увеличилась в 1,93 раза. Относительно меньшая динамика роста имела место для высших учебных заведений таких стран, как Китай и Япония (увеличение доли нематериальных активов здесь произошло в 1,6 и в 1,44 раза соответственно).

Наименьший рост нематериальных активов, среди анализируемых стран, с 2003 по 2018 годы имел место для высших учебных заведений Российской Федерации, доля которых за анализируемый период времени увеличилась лишь в 1,13 раза. Следовательно, высшие учебные заведения именно данной страны значительно уступают конкурентам в объеме нематериальных активов.
Исходя из того, что подавляющая часть нематериальных активов высших учебных заведений в Российской Федерации связана с их человеческими ресурсами [2, с.8], особую значимость приобретают вопросы их эффективного планирования.

В целях модернизации процесса стратегического управления активами высших учебных заведений в Российской Федерации был выделен следующий ряд перспектив планирования их человеческих ресурсов, актуальных на 20192021 годы (рисунке 2). Каждая из обозначенных перспектив была ранжирована безразмерным рейтинговым числом от 0 (значимость перспективы в плановом промежутке времени является минимальной) до 100 единиц (значимость перспективы в плановом промежутке времени является максимальной). При этом совокупный уровень значимости пяти обозначенных перспектив не должен превышать 500 единиц.

Оценка значимости перспективы была проведена методом экономико-математического моделирования на основе привлечения десяти 


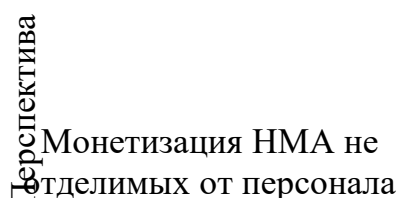

Ориентация на персональные стратегические планы

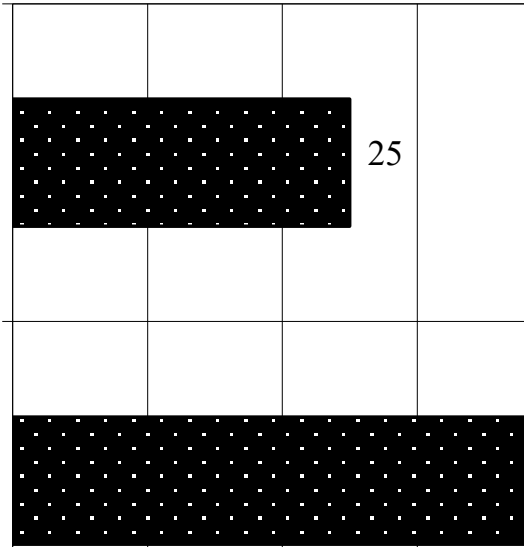

Повышение детализации процесса стратегического планирования

Увеличение горизонта планирования человеских ресурсов ВУЗа

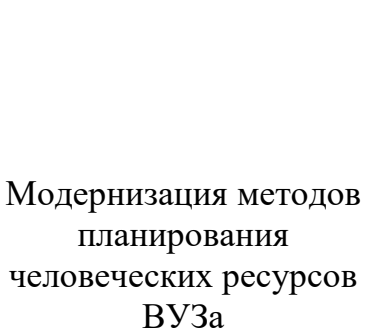
ВУЗа
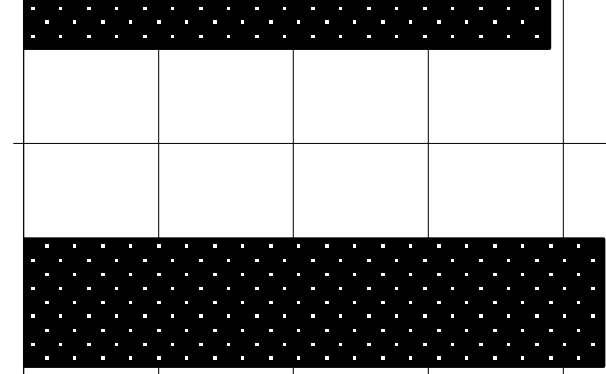

\section{9}

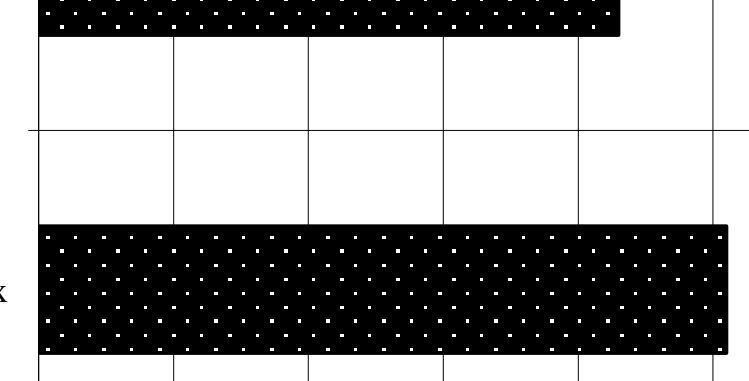

43

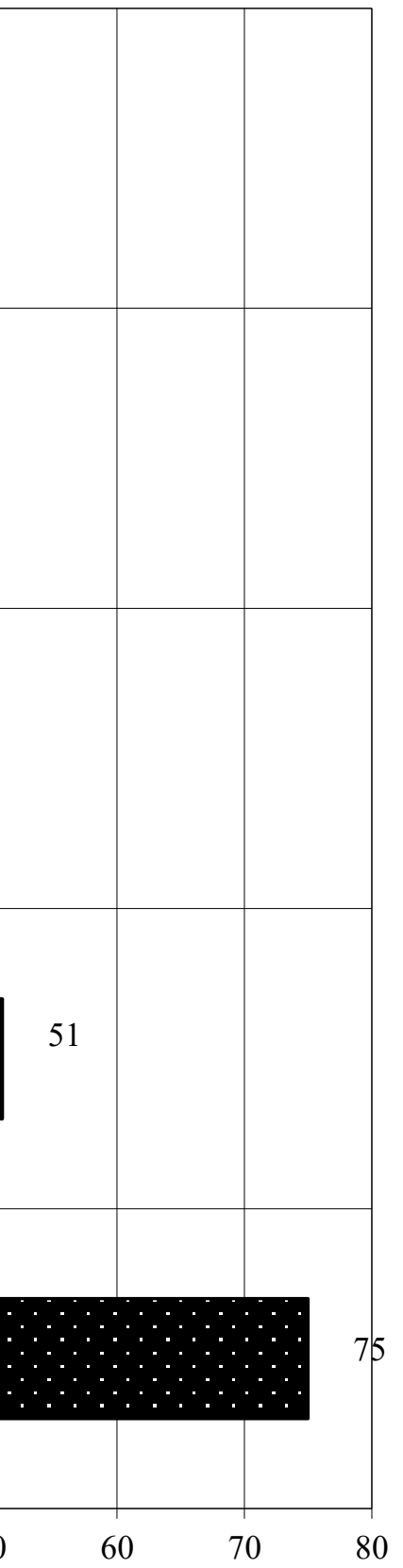

Значимость, ед.

Puc. 2. Актуальные для высших учебных заведений Российской Федерации перспективы планирования их человеческих ресурсов в процессе стратегического управления активами на 2019-2021 годы

экспертов, квалифицированных в анализируемой области знания.

Из рисунка 2 можно увидеть, что одной из основных перспектив планирования человеческих ресурсов в процессе стратегического управления активами высшего учебного заведения в Российской Федерации на 2019-2021 годы является перспектива, связанная с модернизацией методической базы (значимость данной перспективы была определена в 75 единиц из 100 воз- можных). Суть данной перспективы заключена в применении более современных (например, на основе эвристических сценариев планирования и применения нейросетевых математических инструментов) методов и инструментов планирования человеческих ресурсов. В качестве базы для модернизации целесообразно использовать зарубежный опыт передовых в аспекте управления нематериальными активами стран (США, Германия и Китай), адаптированный под нужны 
высших учебных заведений Российской Федерации. Комплексная модернизация методической базы планирования человеческих ресурсов в высших учебных заведениях Российской Федерации в будущем позволит в значительной мере сократить совокупные затраты времени и повысить точность получаемых результатов в стратегической перспективе.

Увеличение горизонта планирования человеческих ресурсов в процессе стратегического управления активами является второй по значимости перспективой с рейтингом в 51 единицу из 100 возможных. Содержание указанной перспективы связано с расширением горизонта планируемых событий в стратегическом плане высшего учебного заведения. Так, например, средний период планирования для высших учебных заведений в Российской Федерации составляет три года в то время, как для такой страны, как Германия - 5 лет и более (отдельные высшие заведения Англии строят формализованные планы в сфере человеческих ресурсов более чем на двадцатилетний период). Здесь же стоит отметить, что увеличение горизонта планирования человеческих ресурсов высшего учебного заведения позволит значительно повысить эффективность использования как материальных, так и нематериальных активов, ввиду повышения соответствия времени их жизненного цикла с плановым периодом управления.

Третья по значимости перспектива стратегического планирования (значимость данной перспективы была определена в 43 единицы из 100 возможных) связана с повышением детализации анализируемого процесса. Так, например, в высших учебных заведениях США формализация одного показателя стратегического плана по человеческим ресурсам в среднем достигается за счет применения не менее девяти первичных (определяющих) показателей. Более того, сам процесс проверки показателей стратегического контура по персоналу осуществляется по трехфазовой основе (одна внутренняя проверка и две внешние) в то время, как в Российской Федерации имеют место не более двух фаз проверки (зачастую, применяется лишь одна внутренняя фаза). При этом в высших учебных заведениях Российской Федерации среднее количество определяющих показателей не превышает четырех единиц. Следовательно, для повышения точности планируемых показателей в сфере человеческих ресурсов высшего учебного заведения необходимо существенным образом пересмотреть их элементарный состав. В среднесрочной и долгосрочной перспективе, что позволит минимизировать ошибки в реализации стратегического плана за счет принятия к рассмотрению более широкого перечня определяющих факторов.

Следующая из рассмотренных перспектив связана с ориентацией на персональные стратегические планы (значимость данной перспективы была определена в 39 единиц из 100 возможных). По последним данным лишь 20 процентов сотрудников высших учебных заведений Российской Федерации имеют четко разработанные стратегические планы индивидуального развития, соответствующие общей стратегической ориентации высшего учебного заведения. При этом лишь менее 5 процентов из указанного количества полностью исполняют содержание указанных планов на практике. Для сравнения в высших учебных заведениях Германии данные показатели составляют 90 и 85 процентов соответственно. Реализация данной перспективы в высших учебных заведениях Российской Федерации позволит значительно модернизировать процесс планирования человеческих ресурсов в аспекте стратегического управления активами.

Заключительной из рассмотренных перспектив (уровень значимости 25 единиц из 100 возможных) является монетизация нематериальных активов, которые неотделимы от персонала. Суть данной перспективы состоит в том, что в настоящее время многие виды нематериальных активов высшего учебного заведения (например, ноу-хау), являются неотделимыми от работающих там сотрудников. Соответственно, монетизация подобных нематериальных активов, отдельно от их носителей, формально, не осуществима. Однако, если активизировать процесс трансформации указанных нематериальных активов в отделимые от индивидуума (например, в патенты, лицензии и прочее) процесс их монетизации для высшего учебного заведения сможет протекать и без участия персонала. Реализация данной перспективы - с одной стороны, позволит повысить уровень доходов, получаемых персоналом высшего учебного заведения и самим высшим учебным заведением (за счет получения премий и иных поощрительных выплат за генерацию нематериальных активов отделимых от индивидуума), а с другой стороны - значительно модернизирует сам про- 
цесс планирования человеческих ресурсов, как таковых.

Таким образом, можно сделать вывод, что для повышения эффективности планирования человеческих ресурсов в процессе стратегического управления активами высшего учебного заведения целесообразно рассмотреть к реализации комплекс перспектив (от модернизации методической базы до повышения детализации процесса планирования), которые позволят значительно улучшить ситуацию, сложившуюся в Российской Федерации в анализируемой сфере.

\section{Библиографический список}

1. Учет нематериальных активов: Положение по бухгалтерскому учету 14/2007 [Электронный ресурс]: Приказ Минфина РФ от 27 декабря 2007 г. № 153н // Справочно-правовая система «Гарант».- Последнее обновление 01.11.2018.

2. Бутко Е.Я. Управление человеческими ресурсами / Е.Я. Бутко // Образовательные ресурсы и технологии. 2016. № 5. С. 3-9.

3. Жамбекова Р.Л., Шеожев Х.В. Стратегическое управление в региональной экономике / Р.Л. Жамбекова, Х.В. Шеожев // Экономические науки. 2012. № 3. С. 87-89.

4. Компания Делойт Туш Томацу Лимитед [Электронный ресурс]: Внутренние аналитические материалы Официальный сайт компании Делойт Туш Томацу Лимитед, 2018.- Режим доступа: https://www2.deloitte. com

5. About SHRM. - Society for Human Resource Management, retrieved 22 December 2011. 